\title{
Ortaokul Öğrencilerinin Duygu Düzenleme Becerileri ile Bilinçli Farkındalık Düzeyleri Arasındaki illișkinin İncelenmesi
}

\author{
Ziya TOPRAK* \\ Sevgi ÇETINER BACAK ${ }^{* *}$
}

\begin{abstract}
Öz: Duygu düzenleme becerileri ile bilinçli farkındalık konuları son dönemlerde önem kazanmaya başlanmış iki problem alanıdır. Duygu düzenlemenin bireylerin sağlıklı davranışlar geliştirmesine yardım ettiğini raporlayan çalışmalar mevcuttur. Benzer şekilde bilinçli farkındalığın da duygu düzenlemeye pozitif katkısı olduğunu belirten çalışmalar bulunmaktadır. Bu çalışma bu literatüre duygu düzenleme ve bilinçli farkındalık arasındaki ilişkiye inceleyerek dahil olmaktadır. Çalışmanın amacı ortaokul öğrencilerinin duygu düzenleme becerileri ile bilinçli farkındalık düzeyleri arasındaki ilişkiyi incelemektir. İlişkisel desende tasarlanan bu araştırma rastgele seçilen 345 öğrencinin katılımı ile gerçekleştirilmiştir. Çalışma bulgularına göre öğrencilerin duygu düzenleme becerileri ile bilinçli farkındalık düzeyleri arasında anlamlı bir ilişki mevcuttur. Çalışma, bulgulardan hareketle, öğrencilerin duygu düzenleme kapasitelerini geliştirme maksadı ile bilinçli farkındalık müdahale programlarının geliştirilmesi ve uygulanmasını önererek sonlanmaktadır.
\end{abstract}

Anahtar Sözcükler: Duygu Düzenleme, Bilinçli Farkındalık, Korelasyon, Ortaokul Öğrencileri.

\section{The Examination of Relationship Between Middle School Students' Emotion Regulation Skills and Mindfulness Level}

\begin{abstract}
Emotion regulation and mindfulness have been gaining importance as two different problematic. There are studies reporting that emotion regulation helps students to develop health behavior patterns. Similarly, there are studies reporting that mindfulness has a positive impact on emotion regulation. The present study is a part of this literature since it examines the relationship between two constructs. The aim this study is to examine the relationship between middle school students' emotion regulation abilities and mindfulness level. This correlational study gathers its data from randomly selected 345 students. Findings indicate that there is a significant association between emotion regulation and mindfulness. The study concludes that mindfulness intervention programs should be developed and put in use in order to develop students' emotion regulation capacities.
\end{abstract}

Keywords: Emotion Regulation, Mindfulness, Correlation, Middle School Students. 
Duygu çalışmaları son dönemde alan yazında sıklıkla karşımıza çıkmaya başlamıştır (Duy ve Yıldız, 2014; Frenzel, Becker-Kurz, Pekrun, Goetz ve Lüdke 2018; Koole, 2010; Phillips ve Power, 2007; Werner ve Gross, 2010). Bu çalışmalarda dikkat çeken ortak vurgu, duyguların gündelik hayatta davranışlarını biçimlendirme ve etkileme kapasitesi olarak ön plana çıkmasıdır. Diğer taraftan duygu çalışmalarına farklı bir boyut katan ve bilincin duygusal ve duyusal süreçler içerisindeki rolünü sorgulayan bilinçli farkındalık araştırmaları da karşımıza sıklıkla çıkmaktadır (Baer, 2009; Brown ve Ryan, 2003; Çıkrıkçı, 2013; Nydahl, 2008; Özyeşil, Arslan, Kesici, ve Deniz, 2011). Bu çalışmalarda, anlık deneyimlere odaklanılarak psikolojik iyilik halinin artırılmasının mümkünlüğü sorgulanmaktadır. Duygu düzenleme ve bilinçli farkındalık her ne kadar iki farklı alan gibi gözükse de, temel olarak psikolojik iyiliği artırmayı hedeflemelerinden dolayı aynı sorunsal ile ilgilendiklerini ifade etmek mümkündür. Bu çalışma bu ifadeyi test etme niteliğinde bir araştırmadır.

Duygu kavramına, sosyoloji (Jacobsen, 2018), felsefe (Ben-Ze'ev, 1997), siyaset (Scribano, 2018) ve psikoloji (Gross ve Thompson, 2007) gibi farklı disiplinlerde farklı yaklaşımlar olmak ile birlikte, kavramın özellikle psikoloji alanında özel bir çalışma alanı olarak belirdiğini vurgulamakta yarar vardır. Duygu düzenleme kavramının daha iyi anlaşılması için kuşkusuz öncelikle düzenlenen kavramdan ne anlaşıldığının ifade edilmesi gereklidir. Kimi zaman bireye yardım eden ve kimi zaman zarar veren duyguların üç temel özelliği bulunmaktadır (Gross ve Thompson, 2007, s. 4-5). Öncelikle duygular, bireyin arzu ve hedefleri ile ilişkili bir durumda olduğunda ortaya çıkar. Örneğin bir taraftarda maç izlemesi esnasında, bir öğrencide sınav esnasında ya da yaşamsal bir tehlike esnasında (deprem gibi) ortaya çıkarlar. İkinci temel özellik duyguların çok yönlü olmasıdır. Bu özellikle ifade edilmek istenen duyguların kapsayıcı ve davranışsal sonuçlarının bulunduğudur (Gross ve Thompson, 2007, s. 5). Psikolojik bir süreç yada süreçler bütünü olarak duygu çok boyutlu bir kavram olmakla birlikte geniş anlamda bireyin duygusal deneyimlerini tanıması, anlaması, kabul etmesi, stres altındayken dürtülerini kontrol etmesi ve duruma uygun esnek duygusal tepkiler verebilme kapasitesi olarak tanımlanabilir (Gouveia, Canavarro ve Moreira, 2019). Duygular farklı hissetmelere neden olur ve bunlar da farklı tepkilere yol açar. Son olarak duygular düzenlenebilirdir. Bu son önerme, diğer pek çok çalışma gibi bu araştırmanın da temel çıkış noktasını olmuştur.

Geniş anlamı ile duygu düzenleme bireylerin duyguları kontrol etmede kullandığı stratejileri ifade etmektedir (Gross, 1998; Gross ve John, 2003). Bu stratejiler temel olarak arzuların ve hedeflerin gerçekleştirilmesi için geliştirilebileceği gibi stres altında oluşabilecek negatif duyguları kontrol etmeyi de hedefleyebilir. Bu bağlamda duygular yoğunluğu artırma yada azaltma biçiminde düzenlenebilir. Bahsi geçen stratejilerden bilişsel denetleme ve dışavurumcu baskılama en çok kullanılanlardandır (Webb, Miles ve Sheeran, 2012). Bilişsel denetleme ortaya çıkan duyguları duruma göre yapılandırmayı ifade ederken, bastırma stratejisi var olan duygu ve durumu içselleştirmeyi içermektedir. Doğru zamanlarda kullanıldıklarında her iki strateji de duygu düzenlemede oldukça etkili olabilmektedir (Neff, 2003). Bununla birlikte bu stratejilerin, özellikle de baskılama stratejisinin uygunsuz ve aşırı kullanılmasının şiddet davranışlarını da içeren olumsuz sonuçlara da yol açtığı bildirilmektedir (Gillespie, Garofale ve Velotti, 2018; Norström ve Pape, 2010).

Bu stratejileri doğru bir şekilde kullanabilen ergenler daha sağlıklı psikolojik ve sosyal olarak kabul edilebilir davranışlar sergileyebilir. Buna karşın, bu stratejilerden yoksun olanlar duygu düzenlemede zorluklarla karşılaşmaktadırlar (Stevenson, Milings ve Emerson, 2019). Duygu düzenleme becerilerinden yoksun olan ergenlerin çeşitli psikopatolojiler geliştirmeye daha yatkın oldukları raporlanmaktadır (Hoffman, Sawyer, Fang ve Asnaani, 2012). Yeme bozuklukları, obezite, cinsel suçlar, ve depresyon bu patolojilerden bazılarıdır (Gillespie ve diğerleri, 2018; Gouveia ve diğerleri, 2019; Kaufman ve diğerleri, 2015; Sperberg ve Stabb, 1998; Stevenson ve diğerleri, 2019). Bu çalışmalardan ortaya çıkan ortak nokta duygu düzenlemenin psikopatolojik risklerin önceden belirlenmesinde oynayabileceği potansiyelidir. $\mathrm{Bu}$ noktada duydu düzenleme hususunun özellikle ergenler düzeyinde çalışılması ve duygu düzenlemeye katkıda bulunma ihtimali olan kavramları ile ilişkisinin incelenmesi oldukça önem kazanmaktadır. Bu kavramlardan biri olan bilinçli farkındalığın uyumlu ve sağlıklı bir duygusal düzenleme kapasitesinin geliştirilmesine katkıda bulunma potansiyeli bulunmaktadır.

Farkındalık ya da bilinçli farkındalık belli bir anda gerçekleşen deneyimlere dikkat kesilme halidir (Brown 
ve Ryan, 2003). Şimdide gerçekleşen deneyimlere yargısız farkında olma hali olan bilinçli farkındalık bu halin sürekliliği ile ilgilenir. Özyeşil ve diğerleri (2011) bilinçli farkındalığın bir anlar toplamı olduğunu ve bu anların ortak yönlerinin bulunduğunu, Germer, Siegel ve Fulton (2005)'dan aktarır. Buna göre bu anlar;

1. Kavramsal değildir (nonconceptual): Bilinçli farkındalık, düşünce süreçlerinden geçmeden meydana gelen farkındalık halidir.

2. Şimdi odaklıdır (present- centered): Bilinçli farkındalık, her zaman şimdiki andadır. Yaşadıklarımız hakkındaki düşüncelerimiz şu anın bir adım sonrasıdır.

3. Yargılayıcı değildir (nonjudgemental): Eğer yaşadıklarımızın bundan farklı olmasını istiyorsak, farkındalık serbest bir şekilde oluşmaz.

4. Maksatlıdır (intentional): Bilinçli farkındalık, her zaman belirli bir yere yönlendirilmiş dikkati gerektirir. Dikkatini şimdiki ana tekrar yönlendirme, bilinçli farkındalığa zaman içinde süreklilik kazandırır.

5. Katılımcı gözlemi gerektirir (participant observation): Bilinçli farkındalık, olayların dışında ilgisiz bir gözlemcilik değildir, zihin ve bedeni daha yakından hissetmektir.

6. Sözel değildir (nonverbal): Bilinçli farkındalık deneyimi, sözün esareti altında değildir; çünkü farkındalık, kelimeler zihinde ortaya çıkmadan önce oluşur.

7. Keşfe dayalıdır (exploratory): Bilinçli farkındalık, her zaman algının daha ince düzeylerini araştırır.

8. Özgürleştiricidir (liberating): Bilinçli farkındalık, her anı koşullanılmış kederlenmeden kurtulmayı sağlar. (Özyeşil ve diğerleri, 2011, s. 226-27)

Baer, Smith, Hopkins, Krietemeyer, ve Toney (2006) kullanımda olan farklı bilinçli farkındalık ölçeklerini detaylı bir şekilde inceleyerek, bilinçli farkındalığın çok yüzlü olduğunu belirtir ve beş farklı boyutun ön plana çıktı̆ıın ifade ederler. Bu boyutlar, gözleme (çevresel ve içsel uyarıcıların farkında olma), tanımlama (bireyin kendi deneyimini ifade edebilmesi), yargılamama (deneyimleri hemen değerlendirmeme, yargıya varmama), farkında olarak davranma (davranışlara dikkat kesilme) ve tepki vermeme (düşünce ve duyguları tepki vermeden deneyimleme) olarak özetlenebilir (Bear ve diğerleri, 2006; Stevenson ve diğerleri, 2019).

Gerek Özyeşil ve diğerlerinin (2011), gerekse Baer ve diğerlerinin (2006) aktardıklarından çıkan ortak nokta kabul etme, kabullenme ya da yargılamamadır. Farklı çalışmalar, yargılamama ve kabul etme halinin bilinçli farkındalığı artırarak duygu düzenlemeyi kolaylaştırdığını ifade etmektedir (Gross, 2002; Hayes ve Feldman, 2004; Martin, 1997; Teasdale, 1999). Artan bilinçli farkındalık, duygu düzenlemeye olumlu katkı yaptı̆̆ından yaşanması muhtemel psikolojik problemlerin oluşma ihtimalini azaltma potansiyeli taşımaktadır. Bilinçli farkındalık ve yargısız kabul etme becerilerinin şimdi olan deneyimlere uygulanması bireylerin duygu düzenleme becerilerine ve psikolojik iyilik olma hallerine katkıda bulunmaktadır (Brown, Ryan ve Craswell, 2007). Duygusal düzenleme kapasitesi yüksek olan bireylerin daha sağlıklı davranışlar sergileyeceği açıktır. $\mathrm{Bu}$ durumda bireylerin bu kapasitelerinin belirlenmesi, özellikle ergenlik dönemindeyken belirlenmesi, oldukça önem kazanmaktadır. Sağlıksız davranışların önceden belirlenmesi bireylerin bu tür davranışlarını düzeltme şansını artırmaktadır. Bu bağlamda bu çalışma sağlıksız davranış öncülü olarak ergenlerin bilinçli farkındalık ve duygusal düzenleme kapasitelerini incelemektedir. Bu amaç doğrultusunda şu sorular sorulmuştur;

1. Ortaokul öğrencilerinin bilinçli farkındalık ve duygu düzenleme becerileri nelerdir?

2. Ortaokul öğrencilerinin bilinçli farkındalık becerileri ve duygu düzenleme becerileri sınıfa ve cinsiyete göre farklılık göstermekte midir?

3. Ortaokul öğrencilerinin bilinçli farkındalık ve duygu düzenleme becerileri arasında anlamlı bir ilişki var midır?

\section{Yöntem}

Ortaokul öğrencilerinin bilinçli farkındalık ve duygu düzenleme becerileri arasındaki ilişkiyi belirlemeyi amaçlayan bu araştırmada ilişkisel tarama modeli kullanılmıştır (Williams, 2007).

\section{Evren Örneklem}

Araştırmanın evrenini İstanbul ilindeki kamu ortaokullarında okuyan ortaokul (6-8. sınıf) öğrencileri oluşturmaktadır. 5. sınıflar literatürde (10 yaşın altında olduklarından) ergen olarak kabul edilmediği için 
araştırmaya dahil edilmemiştir (Giedd ve diğerleri, 1999; Naveh-Benjamin ve diğerleri, 2009). Araştırmanın evreni olan İstanbul'da ortaokulda 2017-2018 yılı verilerine göre yaklaşık 600.000 öğrenci bulunmaktadır (Milli Eğitim Bakanlığı [MEB], 2019). Araştırmanın örneklemi farklı bölgelerden (Beşiktaş, Kağıthane ve Sultangazi) üç ortaokuldan rastgele seçilen 400 öğrenci oluşturmaktadır. Araştırma kapsamında gerekli güvenirlilik seviyesini sağlamak için 400 öğrencinin yeterli olacağ belirlenmiştir. Katılımın sağlanan 400 öğrenciden verileri eksiksiz olan 345 öğrencinin verileri analize tabi tutulmuştur. Tablo I'de katılımcıların cinsiyetlerine ve sınıflarına göre dağılımı izlenmektedir.

Tablo I

Katılımcıların Bă̆ımsız Değişkenlere Göre Dă̆ılımı

\begin{tabular}{llll}
\hline & & $\mathbf{f}$ & $\mathbf{\%}$ \\
\hline \multirow{3}{*}{ Cinsiyet } & Erkek & 182 & 52.8 \\
\cline { 2 - 4 } & K1z & 163 & 47.2 \\
\cline { 2 - 4 } & Toplam & 345 & 100 \\
\hline \multirow{4}{*}{ Sinif } & 6. Sinif & 110 & 31.9 \\
\cline { 2 - 4 } & 7. Sinif & 114 & 33 \\
\cline { 2 - 4 } & 8. Sinif & 121 & 35.1 \\
\cline { 2 - 4 } & Toplam & 345 & 100 \\
\hline
\end{tabular}

Veri Toplama Araçları

Araştırmada veri toplamak için Çocuk ve Ergenler İçin Bilinçlilik Ölçeği (ÇEİBÖ) ve Ergenler İçin Duygu Düzenleme Ölçeği (EIDDÖ) kullanılmıştır.

ÇEİB ölçeğinin orijinali Greco, Baer ve Smith (2011) tarafından geliştirilmiş olup 5'li likert tipindedir. Cronbach Alfa değeri . 80 olarak bulunmuş ve tek faktörlü yapısı doğrulanmıştır (RMSEA = .07, SRMR= .06, $\mathrm{NNFI}=.87, \mathrm{CFI}=.90)$. Türkçeye adaptasyonu Çıkrıkçı (2016) tarafından gerçekleştirilmiştir. Adaptasyonun Cronbach Alfa değeri .73 olarak bulunmuş olup, ölçeğin tek faktörlü yapısı doğrulanmıştır (RMSEA= .06, TLI= .91, GFI= .97, CFI= .93). Ölçek kapsamında 2' den düşük puanlar "düşük", 2-3 aralığı "orta", ve 3'ten yüksek puanlar "yüksek" olarak değerlendirilmektedir.

EIDDÖ ölçeğinin orijinali Phillips ve Power (2007) tarafından ergenlerin duygu düzenleme becerilerini belirlemek amacı ile geliştirilmiştir. İçsel işlevsel duygu düzenleme, dışsal işlevsel duygu düzenleme, içsel işlevsel olmayan duygu düzenleme ve dişsal işlevsel olmayan duygu düzenleme olmak üzere dört alt boyuttan oluşan ölçek, 5'li likert tipi olup 18 maddeden oluşmaktadır. İşlevsel olan boyutlar olumlu duygu düzenleme becerilerini ifade ederken, işlevsel olmayan boyutlar olumsuz duygu düzenleme becerilerini ifade etmektedir. Dolayısı ile katılımcıların işlevsel boyutlardan yüksek puan almaları, işlevsel olmayan boyutlardan düşük puan almaları katılımcıların sağlıklı duygu düzenleme becerilerine sahip olduğu anlamına gelmektedir. Ölçek kapsamında 2'den düşük puanlar "düşük", 2-3 aralığ1 "orta" ve 3'ten yüksek puanlar "yüksek" olarak değerlendirilmektedir. Duy ve Yıldız (2014) tarafından adaptasyonu yapılan ölçeğin uyum indeksleri değerleri kabul edilebilir bulunmuştur (RMSEA $=.06, \mathrm{RMR}=.09, \mathrm{SRMR}=.06$, GFI= .94, AGFI= .92, $\mathrm{CFI}=.93, \mathrm{NFI}=.91$ ve $\mathrm{NNFI}=.92$ ).

\section{Veri Analizi}

Ortaokul öğrencilerinden toplanan verilerin normal dağılım gösterdiği belirlendikten sonra parametrik test teknikleri kullanılmıştır. SPSS 24 paket programı kullanılarak bağımsız örneklem t-testi, ANOVA ve Pearson korelasyon kat sayısından yararlanılmıştır. Hipotezler .95 güven aralığı ve hata olasılığı .05 düzeyi kullanılarak kabul edilmiş ya da reddedilmiştir.

\section{Bulgular}

\section{Birinci Alt Probleme İlişkin Bulgular}

Çalışmanın birinci alt problemi katılımcıların Bilinçli Farkındalık ve duygu düzenleme becerilerinin seviyesini belirlemek ile ilgilidir. Tablo II'de katılımcıların ilgili değişkenlere göre dağılımı izlenmektedir. 
Tablo II

Katılımcların Bilinçli Farkındalık ve Duygu Düzenleme Becerileri

\begin{tabular}{lccc}
\hline & $\mathbf{N}$ & $\overline{\mathbf{X}}$ & ss \\
\hline Bilinçli Farkındalık & 345 & 2.84 & .86 \\
İç İşlevsel Duygu Düzenleme & 345 & 4.10 & .67 \\
Diș İşlevsel Duygu Düzenleme & 345 & 3.44 & .85 \\
İç İşlevsel Olmayan Duygu Düzenleme & 345 & 2.09 & .79 \\
Diş ̇̇şlevsel Olmayan Duygu Düzenleme & 345 & 1.55 & .54 \\
\hline
\end{tabular}

Tablo incelendiğinde katılımcıların bilinçli farkındalık düzeylerinin orta seviyede olduğu görülmektedir $(\overline{\mathrm{X}}=2.84, \mathrm{ss}=.86)$. Katılımcıların iç işlevsel duygu düzenleme alt boyutu ortalamaları 4.10 olarak gerçekleşmiştir $(\overline{\mathrm{X}}=4.10, \mathrm{ss}=.67)$. Öğrencilerin dış işlevsel duygu düzenleme ortalamasının 3.44 olduğu izlenmektedir $(\overline{\mathrm{X}}=3.44$, $\mathrm{ss}=. .85)$. Katılımcların iç işlevsel olmayan duygu düzenleme alt boyutu ortalamaları 2.09 olarak gerçekleşmiştir ( $\bar{X}=2.09$, ss=.79). Öğrencilerin dış işlevsel olmayan duygu düzenleme ortalamasının 1.55 olduğu izlenmektedir ( $\overline{\mathrm{X}}=1.55$, ss=.54).

\section{İkinci Alt Probleme İlişkin Bulgular}

Çalışmanın ikinci alt problemi katılımcıların bilinçli farkındalık ve duygu düzenleme becerilerinin sınıfa ve cinsiyete göre farklılık gösterip göstermediği ile ilgilidir. Katılımcıların cinsiyete göre farklılıkları bağımsız örneklem t-testi ve sınıflara göre farklılıkları tek yönlü varyans analizi testi ile incelenmiştir. Tablo III'te kalıtımcıların Bilinçli Farkındalık ve duygu düzenleme becerilerinin cinsiyetlerine göre farkına bakılmıştır.

Tablo III

Katılımcıların Bilinçli Farkındalık ve Duygu Düzenleme Becerilerinin Cinsiyetlerine Göre Farklılıkları

\begin{tabular}{|c|c|c|c|c|c|c|c|}
\hline & Cinsiyet & $\mathrm{N}$ & $\overline{\mathrm{X}}$ & SS & Stand. Hata & $\mathrm{t}$ & $\mathrm{p}$ \\
\hline \multirow{2}{*}{ Bilinçli Farkındalık } & Erkek & 182 & 2.89 & .89 & \multirow{2}{*}{.09} & \multirow{2}{*}{1.277} & \multirow{2}{*}{.20} \\
\hline & $\mathrm{K}_{1 \mathrm{Z}}$ & 163 & 2.77 & .80 & & & \\
\hline \multirow{2}{*}{ İç İşlevsel DD } & Erkek & 182 & 4.11 & .70 & \multirow{2}{*}{.07} & \multirow{2}{*}{.283} & \multirow{2}{*}{.77} \\
\hline & $\mathrm{K}_{1 \mathrm{Z}}$ & 163 & 4.09 & .63 & & & \\
\hline \multirow{2}{*}{ Dış İşlevsel DD } & Erkek & 182 & 3.50 & .89 & \multirow{2}{*}{.09} & \multirow{2}{*}{1.29} & \multirow{2}{*}{.31} \\
\hline & $\mathrm{K}_{1 \mathrm{Z}}$ & 163 & 3.38 & .79 & & & \\
\hline \multirow{2}{*}{ İç İşlevsel Olmayan DD } & Erkek & 182 & 2.10 & .79 & \multirow{2}{*}{.08} & \multirow{2}{*}{.11} & \multirow{2}{*}{.91} \\
\hline & $\mathrm{K} 1 \mathrm{Z}$ & 163 & 2.09 & .79 & & & \\
\hline \multirow{2}{*}{ Diş İşlevsel Olmayan DD } & Erkek & 182 & 1.51 & .52 & \multirow{2}{*}{.06} & \multirow{2}{*}{-1.02} & \multirow{2}{*}{.19} \\
\hline & $\mathrm{KIZ}$ & 163 & 1.58 & .58 & & & \\
\hline
\end{tabular}

Tablo III'ten öğrencilerin cinsiyetine göre bilinçli farkındalık ve duygu düzenleme becerilerine arasındaki farkı incelemek için gerçekleştirilen bağımsız örneklem t-testi sonuçları izlenmektedir. Buna göre öğrencilerin cinsiyetlerine göre bilinçli farkındalık ortalamaları arasında anlamlı bir fark bulunmamıştır $\left(\overline{\mathrm{X}}_{\text {erkek }}=2.89\right.$, ss $=.89$, $\overline{\mathrm{X}}_{\mathrm{kz}}=2.77, \mathrm{ss}=.80, \mathrm{p}=.20$ ). Benzer şekilde katılımcıların cinsiyetlerine göre iç işlevsel ortalamaları ( $\overline{\mathrm{X}}_{\text {erkek}}=4.11$, $\left.\mathrm{ss}=.70, \overline{\mathrm{X}}_{\mathrm{kz}}=4.09, \mathrm{ss}=.63, \mathrm{p}=.77\right)$, dış işlevsel ortalamaları $\left(\overline{\mathrm{X}}_{\text {erkek }}=3.59, \mathrm{ss}=.89 \overline{\mathrm{X}}_{\mathrm{kz} z}=3.38, \mathrm{ss}=.79, \mathrm{p}=.31\right)$, iç işlevsel olmayan ortalamaları ( $\left.\overline{\mathrm{X}}_{\text {erkek }}=2.10, \mathrm{ss}=.79 \overline{\mathrm{X}}_{\mathrm{kz}}=2.09, \mathrm{ss}=.79, \mathrm{p}=.91\right)$ ve dış işlevsel olmayan ortalamaları $\left(\overline{\mathrm{X}}_{\text {erkek }}=1.51, \mathrm{ss}=.52 \overline{\mathrm{X}}_{\mathrm{kz}}=1.58, \mathrm{ss}=.58, \mathrm{p}=.19\right.$ ) arasında da anlamlı bir fark bulunamamıştır.

Tablo IV'ten katılımcıların sınıflarına göre bilinçli farkındalık ve duygu düzenleme becerileri farklılıkları izlenmektedir.

Tablo IV

Katılımcıların Bilinçli Farkındalık ve Duygu Düzenleme Becerilerinin Sınıflarına Göre Farklılıkları

\begin{tabular}{|c|c|c|c|c|c|c|}
\hline & & Kareler. Toplamı & sd & Kareler Ort. & $\mathrm{F}$ & $\mathrm{p}$ \\
\hline \multirow{3}{*}{ Bilinçli Farkındalık } & Gruplar Arası & 2.41 & 2 & 1.207 & 1.655 & .193 \\
\hline & Grup İçi & 249.385 & 342 & .729 & & \\
\hline & Toplam & 251.800 & 344 & & & \\
\hline \multirow{3}{*}{ İç İşlevsel DD } & Gruplar Arası & .546 & 2 & .273 & .609 & .544 \\
\hline & Grup İçi & 153.197 & 342 & .448 & & \\
\hline & Toplam & 153.743 & 344 & & & \\
\hline \multirow{3}{*}{ Dış İşlevsel DD } & Gruplar Arası & 3.780 & 2 & 1.890 & 2.659 & .071 \\
\hline & Grup İçi & 243.084 & 342 & .711 & & \\
\hline & Toplam & 246.863 & 344 & & & \\
\hline
\end{tabular}


Ortaokul Öğrencilerinin Duygu Düzenleme Becerileri...

\begin{tabular}{|c|c|c|c|c|c|c|}
\hline \multirow{3}{*}{ İç İşlevsel Olmayan DD } & Gruplar Arası & 1.337 & 2 & .669 & 1.069 & .344 \\
\hline & Grup İçi & 213.857 & 342 & .625 & & \\
\hline & Toplam & 215.195 & 344 & & & \\
\hline \multirow{3}{*}{ Diş İşlevsel Olmayan DD } & Gruplar Arası & 3.067 & 2 & 1.533 & 5.405 & .005 \\
\hline & Grup İçi & 97.029 & 342 & .284 & & \\
\hline & Toplam & 100.096 & 344 & & & \\
\hline
\end{tabular}

Tablo IV'ten öğrencilerin sınıflarına göre bilinçli farkındalık ve duygu düzenleme becerilerine arasındaki farkı incelemek için gerçekleştirilen tek-yönlü ANOVA sonuçları izlenmektedir. Buna göre öğrencilerin bilinçli farkındalık düzeyleri arasında anlamlı bir fark oluşmamıştır (Fbilinçli farkndalık =1.655, p=.193). Benzer şekilde öğrencilerin sınıflarına göre iç işlevsel duygu düzenleme becerileri arasında ( $\left.\mathrm{F}_{\text {iç } \text { islevsel } \mathrm{DD}}=.609, \mathrm{p}=.544\right)$, dış işlevsel duygu düzenleme becerileri arasında $\left(F_{\text {dı̧̣ işlevsel } \mathrm{DD}}=2.659, \mathrm{p}=.071\right)$ ve iç işlevsel olmayan duygu

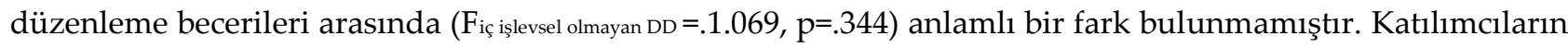
sınıflarına göre dış işlevsel olmayan becerileri arasında anlamlı bir fark ortaya çıkmıştır ( $F_{\text {dıs }}$ islevsel olmayan DD $=5.405, \mathrm{p}=.005)$. Bonferrini testine göre bu fark 6. Sınıflar ile 8. Sınıflar arasında gerçekleşmiştir $\left(\overline{\mathrm{X}}_{\mathrm{fark}}=-.223\right.$, $\mathrm{p}=.004)$.

\section{Üçüncü Alt Probleme İlişkin Bulgular}

Çalışmanın üçüncü alt problemi öğrencilerin bilinçli farkındalık becerileri ve duygu düzenleme becerileri arasındaki ilişki ile ilgilidir. Tablo V'te bu ilişki izlenmektedir.

Tablo V

Katılımcıların Bilinçli Farkındalık ve Duygu Düzenleme Becerileri Arasındaki İlişki

\begin{tabular}{|c|c|c|c|c|c|c|}
\hline & & Bilinçli Farkındalık & İç İşlevsel DD & Dış İşlevsel DD & $\begin{array}{c}\text { İç İşlevsel } \\
\text { Olmayan DD }\end{array}$ & $\begin{array}{c}\text { Diş İşlevsel } \\
\text { Olmayan DD }\end{array}$ \\
\hline \multirow{3}{*}{ Bilinçli Farkındalık } & $\mathrm{r}$ & 1 & $.353^{* *}$ & .499 & $-.299^{* *}$ & $-.308^{* *}$ \\
\hline & $\mathrm{p}$ & & .000 & .000 & .000 & .000 \\
\hline & $\mathrm{N}$ & 345 & 345 & 345 & 345 & 345 \\
\hline \multirow{3}{*}{ İç İşlevsel DD } & $\mathrm{r}$ & $.353^{* *}$ & 1 & $.357^{* *}$ & $-.288^{* *}$ & $-.370^{* *}$ \\
\hline & $\mathrm{p}$ & .000 & & .000 & .000 & .000 \\
\hline & $\mathrm{N}$ & 345 & 345 & 345 & 345 & 345 \\
\hline \multirow{3}{*}{ Dış İşlevsel DD } & $\mathrm{r}$ & $.499^{* *}$ & $.357^{* *}$ & 1 & $-.252^{* *}$ & $-.140^{* *}$ \\
\hline & $\mathrm{p}$ & .000 & .000 & & .000 & .009 \\
\hline & $\mathrm{N}$ & 345 & 345 & 345 & 345 & 345 \\
\hline \multirow{3}{*}{$\begin{array}{l}\text { İç İşlevsel } \\
\text { Olmayan DD }\end{array}$} & $\mathrm{r}$ & $-.299^{* *}$ & $-.288^{* *}$ & $-.252^{* *}$ & 1 & $.241^{* *}$ \\
\hline & $\mathrm{p}$ & .000 & .000 & .000 & & .000 \\
\hline & $\mathrm{N}$ & 345 & 345 & 345 & 345 & 345 \\
\hline \multirow{3}{*}{$\begin{array}{l}\text { Diş İşlevsel } \\
\text { Olmayan DD }\end{array}$} & $\mathrm{r}$ & $-.308^{* *}$ & $-.370^{* *}$ & $-.140^{* *}$ & $.241^{* *}$ & 1 \\
\hline & $\mathrm{p}$ & .000 & .000 & .000 & .000 & \\
\hline & $\mathrm{N}$ & 345 & 345 & 345 & 345 & 345 \\
\hline
\end{tabular}

** 0.001 düzeyinde anlaml

Tablo V'te bulunan Pearson korelasyon analizi sonuçlarına göre katılımcların bilinçli farkındalık becerileri ile duygu düzenleme becerileri arasında anlamı ilişkiler bulunmaktadır. Buna göre bilinçli farkındalık becerileri ile iç işlevsel duygu düzenleme becerileri $(\mathrm{r}=.353, \mathrm{p}<.001)$, ile dış işlevsel duygu düzenleme becerileri $(\mathrm{r}=.499, \mathrm{p}<.001)$ arasında pozitif yönde ve iç işlevsel olmayan duygu düzenleme becerileri $(\mathrm{r}=-299 ., \mathrm{p}<.001)$, ile diş işlevsel olmayan duygu düzenleme becerileri $(\mathrm{r}=-.308, \mathrm{p}<.001)$, arasında negatif yönlü anlamlı ilişki bulunmaktadır. Benzer şekilde iç işlevsel duygu düzenleme becerileri dış işlevsel duygu düzenleme becerileri ile pozitif yönde anlamı bir ilişkiye sahipken ( $\mathrm{r}=.357, \mathrm{p}<.001)$, iç işlevsel olmayan duygu düzenleme $(r=-.288, p<.000)$ ve diş işlevsel olmayan düzenleme $(r=-.370, p<.001)$ ile negatif yönlü anlamlı bir ilişkiye sahiptir. Dış işlevsel duygu düzenleme değişkeni ise iç işlevsel olmayan duygu düzenleme ( $\mathrm{r}=-.252$, $\mathrm{p}<.001)$ ve diş işlevsel olmayan duygu düzenleme $(\mathrm{r}=-.140, \mathrm{p}<.001)$ değişkenleri ile negatif yönlü anlamlı ilişkiye sahiptir. Son olarak iç işlevsel olmayan duygu düzenleme ile dış işlevsel olmayan duygu düzenleme arasında pozitif yönlü anlamlı bir ilişki mevcuttur ( $\mathrm{r}=.241, \mathrm{p}<.001)$. 


\section{Sonuç ve Tartışma}

$\mathrm{Bu}$ çalışmada ortaokul öğrencilerinin bilinçli farkındalık becerileri ile duygu düzenleme becerileri arasındaki ilişki incelenmiştir. Farklı araştırmalar psikopatoloji ve bahsi geçen becerilerin eksikliği arasında anlamlı ilişkiler bulmuştur (Cisler ve Olatunji, 2012; Dalrymple, Clark ve Chelminski, 2018; Levin, Dalarymple, Himes ve Zimmerman, 2014). Bu bağlamda bu becerilerin geliştirilmesi oldukça önem kazanmaktadır.

Araştırma kapsamında üç farklı alt problem teste tabi tutulmuştur. Bu problemler, öğrencilerin duygu düzenleme ve bilinçli farkındalık becerileri, bu becerilerin öğrencilerin cinsiyet ve yaşlarına göre değişip değişmediği ve bu beceriler arasındaki ilişki ile ilgilidir. Kısaca belirtmek gerekirse, öğrencilerin duygu düzenleme becerileri ve bilinçli farkındalık becerileri orta seviyede çıkmıştır. Cinsiyet ve sınıflara göre önemli bir fark bulunmamıştır ve son olarak öğrencilerin bu becerileri arasında beklenti dahilinde anlamlı ilişkiler bulunmuştur.

Bu çalışmanın ilk problemi öğrencilerin duygu düzenleme ve bilinçli farkındalık seviyelerini belirlemek ile ilgilidir. Bulgulara göre öğrencilerin işlevsel olan duygu düzenleme becerileri tatminkar bir seviyede çıkmıştır. İşlevsel olmayan duygu düzenleme becerilerinin düşük kalması ideal bir durumdur ve bu araştırmanın sonuçları da bu duruma yakın sonuçlar elde etmiştir. Bilinçli farkındalık seviyesi araştırmaya katılan öğrenciler arasında orta seviyede bulunmuştur. Bu sonuç öğrencilerin bu becerilerinin geliştirilebileceğini düşündürtmektedir. Bu bağlamda geliştirilen çeşitli programlar bilinçli farkındalık seviyesini artırmayı başarmışlardır (Allen ve diğerleri, 2006; Broderick ve Metz, 2009; Özyeşil, 2011 ).

Çalışmanın ikinci problemi katılımcıların duygu düzenleme ve bilinçli farkındalık becerilerinin cinsiyete ve sınıfa göre değişip değişmediği ile ilgilidir. Çalışma sonuçlarına göre katılımcıların duygu düzenleme ve bilinçli farkındalık becerileri cinsiyetlerine göre değişmemektedir. Her ne kadar ortaokul öğrencileri ile ilgili benzer bir çalışma olmasa da farlı örneklemler ile yapılan çalışmalarda bulunan sonuçlarla bu çalışmada ulaşılan sonuçlar bu nokta örtüşmektedir (Cisler ve Olatunji, 2012; Gillespie ve diğerleri, 2018). Öte taraftan katılımcıların sınıflarına göre farklılıkları noktasında bu çalışmada ortaya çıkan sonuçlar diğer araştırma bulguları ile örtüşmemektedir. Çalışmaya katılan öğrencilerin farklı sınıflarda olması onların farklı yaşlarda olduğu anlamına geldiğinden diğer çalı̧maların yaş bulguları ile kıyaslama yapmak mümkündür. Örneğin Acer (2018) 220 rehber öğretmen ile yaptığı çalışmasında yaşın hem duygu düzenlemede hem de bilinçli farkındalıkta bir faktör olduğunu bulmuştur. Buna göre katılımcıların yaşları arttığında bu becerileri de artmaktadır. Bu çalışmada ise böyle bir farka rastlanmamıştır. Katılımcıların yaşlarına (sınıflarına) göre bilinçli farkındalık becerileri farklılaşmamaktadır. Duygu düzenleme noktasında sadece dış işlevsel olmayan duygu düzenleme becerilerinde bir fark bulunmuştur.

Çalışmada son olarak katılımcıların duygu düzenleme ve bilinçli farkındalık becerileri arasındaki ilişkiye bakılmıştır. Buna göre katılımcıların bu becerileri arasında anlamlı bir ilişkili bulunmuştur. Katılımcıların bilinçli farkındalık becerileri ile işlevsel olan duygu düzenleme stratejileri arasında pozitif yönde ve anlamlı, işlevsel olmayan duygu düzenleme stratejileri arasında negatif yönde anlamı ilişki bulunmuştur. Bu sonuçlar Acer (2018)'in bulguları ile tamamen örtüşmektedir. Benzer bulgular farklı araştırmalarda da ortaya çıkmıştır (Campbell, Lanthier, Weiss ve Shaine, 2019, Flook ve diğerleri, 2010; Gratz ve Roemer, 2004). Alan yazın dikkatli bir şekilde incelendiğinde duygu düzenlemenin sağlıklı öğrenci davranışları ve psikolojik iyilik için oldukça kritik bir öneme sahip olduğu görüşü ağır basmaktadır. Benzer şekilde bilinçli farkındalık ile duygu düzenleme stratejileri arasındaki korelasyon bir çok çalışmanın ulaştığı sonuç olmuştur.

Bu çalışmamanın yazarları alan yazındaki bu gelişmeyi önemli görmekte ve tartı̧̧manın bu noktaya yoğunlaşmaya gerektiğini düşünmektedirler. Flook ve diğerleri (2010) yaptıkları çalışmada geliştirdikleri bilinçli farkındalık programı ile ilk okul öğrencilerinin duygu düzenleme stratejilerinin geliştiğini bulmuşlardır. Bu durumun da öğrencilerin genel davranışlarının gelişmesi ile sonuçlandığını belirtmişlerdir. Benzer şekilde Potek (2012) lise öğrencileri yaptığı çalışmada geliştirdiği bilinçli farkındalık müdahale programı ile öğrencilerin stres ve kaygı seviyesinde azalma ve duygu düzenleme stratejilerinde gelişim gözlemiştir. Paralel bir sonuca Shahidi, Akbari ve Zargari (2017)'de ulaşmıştır. Kadın lise öğrencileri ile 
yaptıkları çalışmada bilinçli farkındalık programının sınav kaygısını anlamlı bir şekilde düşürdüğünü ve duygu düzenleme stratejilerini olumlu yönde geliştirdiklerini bulmuşlardır.

Alan yazında bu tür çalışmaların sayısı gün gittikçe artmaktadır. Bu çalışmanın önerileri de bu nokta da yoğunlaşmaktır. Bu araştırmada bulunan sonuçların farklı örneklem grupları ile teyit edilmesi önemli nokta olmakla birlikte, bilinçli farkındalık müdahale programlarına ihtiyaç duyulduğu düşünülmektedir. Bu bağlamda geliştirilecek programlara ve programların etkinliğini test eden çalışmalara önemli derecede ihtiyaç vardır.

\section{Kaynaklar}

Acer, Ç. (2018). Okul öncesi öğretmenlerinde bilinçli farkındalık ve duygu düzenleme ilişkisi (Yayınlanmamış yüksek lisans tezi). Bahçeşehir Üniversistesi, İstanbul.

Allen, N.B., Blashki, G., Chambers, R., Ciechomski, L., Gullone, E., ... Hassed, C. (2006). Mindfulness-based psychotherapies: A review of conceptual foundations, empirical evidence and practical considerations. Australian and New Zealand Journal of Psychiatry, 40(4), 285-294.

Baer, R. A. (2009). Self-focused attention and mechanisms of change in mindfulness-based treat-ment. Cognitive Behavior Therapy, 38 (1), 15-20.

Baer, R. A., Smith, G. T., Hopkins, J., Krietemeyer, J. ve Toney, L. (2006). Using self-report assessment methods to explore facets of mindfulness. Assessment, 13(1), 27-45.

Ben-Ze'ev A. (1997). Emotions and morality. Journal of Value Inquiry, 31:195-212

Broderick, P. C. ve Metz, S. (2009). Learning to BREATHE: A pilot trial of a mindfulness curriculum for adolescents. Advances in School Mental Health Promotion, 2(1), 35-46. doi:10.1080/1754730X.2009.9715696

Brown, K. ve Ryan, R. (2003). The benefits of being present: Mindfulness and its role in psychological wellbeing. Journal of Personality and Social Psychology, 84, 822-848.

Brown, K. W., Ryan, R. M. ve Creswell, J. D. (2007). Mindfulness: Theoretical foundations and evidence for its salutary effects. Psychological Inquiry, 18, 211-237.

Campbell, A. J., Lanthier, R. P., Weiss, B. A. ve. Shaine, M. D. (2019). The impact of a schoolwide mindfulness program on adolescent well-being, stress, and emotion regulation: A nonrandomized controlled study in a naturalistic setting. Journal of Child and Adolescent Counseling, 5:1, 1834. doi: 10.1080/23727810.2018.1556989

Cisler, J. M. ve Olatunji, B. O. (2012). Emotion regulation and anxiety disorders. Current Psychiatry Reports, 14(3), 182-187. doi:10.1007/s11920-012-0262-2.

Çıkrıkçı, Ö. (206). Çocuk ve ergenler için bilinçlilik ölçeği Türkçe formunun geçerlik ve güvenirlik çalışması. Kastamonu Eğitim Dergisi, 24(2), 905-916.

Dalrymple, K. L., Clark, H., Chelminski, I. ve Zimmerman, M. (2018). The interaction between mindfulness, emotion regulation, and social anxiety and its association with emotional eating in bariatric surgery candidates. Mindfulness, 9(16), 1780. doi:10.1007/s12671-018-0921-4

Duy, B. ve Yıldız, M.A. (2014). Ergenler için duygu düzenleme ölçeğinin Türkçe'ye uyarlanması. Turkish Psychological Counseling and Guidance Journal, 5(41), 23-35.

Flook, L., Smalley, S., Kitil, M. J., Galla, B. M., Kaiser-Greenland, S. ... Kasari., C., (2010). Effects of mindful awareness practices on executive functions in elementary school children. Journal of Applied School Psychology, 26(1), 70-95. doi: 10.1080/15377900903379125

Frenzel, A. C., Becker-Kurz, B., Pekrun, R., Goetz, T. ve Lüdtke, O. (2018). Emotion transmission in the classroom revisited: A reciprocal effects model of teacher and student enjoyment. Journal of Educational Psychology, 110(5), 628-639. Doi: 10.1037/edu0000228 
Giedd, J. N., Blumenthal, J., Jeffries, N. O., Castellanos, F. X., Liu, H., Zijdenbos, A., . . Rapoport, J. L. (1999). Brain development during childhood and adolescence: A longitudinal MRI study. Nature Neuroscience, 2(10), 861-863. doi: 10.1038/13158

Gillespie, S.M., Garofalo, C. ve Velotti, P. (2018). Emotion regulation, mindfulness, and alexithymia: Specific or general impairments in sexual, violent, and homicide offenders? Journal of Criminal Justice, 58 (September-October), 56-66. doi: 10.1016/j.jcrimjus.2018.07.006

Gratz, K. L. ve Roemer, L. (2004). Multidimensional assessment of emotion regulation and dysregulation: Development, factor structure, and initial validation of the difficulties in emotion regulation scale. Journal of Psychopathology and Behavioral Assessment, 26(1), 41-54. doi: 10.1023/B:JOBA.0000007455.08539.94

Gouveia, M. J., Canavarro, M. C. ve Moreira. (2019). Associations between mindfulness, self-compassion, difficulties in emotion regulation, and emotional eating among adolescents with overweight/obesity. Journal of Child and Family Studies, 28(1), 273-285. doi: 10.1007/s10826-018-1239-5

Greco, L., Baer, R. A. ve Smith, G. T. (2011). Assessing mindfulness in children and adolescents: Development and validation of the Child and Adolescent Mindfulness Measure (CAMM). Psychological Assessment, 23(3), 606-614.

Gross, J. J. (1998). The emerging field of emotion regulation: An integrative review. Review of General Psychology, 2(3), 271-299.

Gross, J. J. (2002). Emotion regulation: Affective, cognitive, and social consequences. Psychophysiology, 85(2), 348-362.

Gross, J. J. ve John, O. P. (2003). Individual differences in two emotion regulation processes: Implications for affect, relationships, and wellbeing. Journal of Personality and Social Psychology, 85(2), 348-362.

Gross, J. J. ve Thompson, R. A. (2007). Emotion regulation: Conceptual foundations. J. J. Gross (Ed.), Handbook of Emotion Regulation içinde (ss. 3-24). New York: Guilford Press.

Hayes, A. M. ve Feldman, G. (2004). Clarifying the construct of mind-fulness in the context of emotion regulation and the process of change in therapy. Clinical Psychology: Science and Practice, 11(3), 255-262.

Hofmann, S. G., Sawyer, A. T., Fang, A. ve Asnaani, A. (2012). Emotion dysregulation model of mood and anxiety disorders. Depression and Anxiety, 29(5), 409-416. doi: 10.1002/da.21888

Jacobsen, H. M. (2018). Emotions, everyday life and sociology. London: Routledge.

Kaufman, E. A., Xia, M., Fosco, G., Yaptangco, M., Skidmore, C. R. ve Crowell, S. E. (2015). The difficulties in Emotion Regulation Scale Short Form (DERS-SF): Validation and replication in adolescent and adult samples. Journal of Psychopathology \& Behavioral Assessment, 38(3), 443-455. doi: 10.1007/s10862-015-9529-3

Koole, S. L. (2010). The psychology of emotion regulation: an integrative review. J. D. Houwerand ve D. Hermans (Ed.), Cognition and emotion: reviews of current research and theories içinde (ss. 128-167). New York: Taylor \& Francis Group.

Levin, M. E., Dalrymple, K., Himes, S. ve Zimmerman, M. (2014). Which facets of mindfulness are related to problematic eating among patients seeking bariatric surgery? Eating Behaviors, 15(2), 298-305. doi: 10.1016/j.eatbeh.2014.03.012

Martin, J. R. (1997). Mindfulness: A proposed common factor. Journal of Psychotherapy Integration, 7(4), 291312.

Milli Eğitim Bakanlığı [MEB]. (2019). Milli eğgitim istatistikleri: 2018-2019 Örgün Eğitim. Ankara: Resmi İstatistik Programı Yayınları. 
Naveh-Benjamin, M., Shing, Y. L., Kilb, A., Werkle-Bergner, M., Lindenberger U. ve Li, S. (2009). Adult age differences in memory for name-face associations: The effects of intentional and incidental learning. Memory, 17(2), 220-232. doi: 10.1080/09658210802222183

Neff, K. D. (2003). The development and validation of a scale to measure self-compassion. Self and Identity, 2(3), 223-250. Doi: 10.1080/15298860309027

Norström, T. ve Pape, H. (2010). Alcohol, suppressed anger and violence. Addiction, 105(9), 1580-1586.

Nydahl, O. (2008). The way things are. UK: O Books.

Özyeşil, Z. (2011). Özanlayış ve bilinçli farkındalık. Ankara: Maya Akademi Yayıncılık.

Özyeşil, Z., Arslan, C., Kesici, Ş. ve Deniz, M. E. (2011). Bilinçli Farkındalık Ölçeği'ni Türkçe'ye uyarlama çalışması. Ĕ̆itim ve Bilim, 36 (160), 224-235.

Phillips, K. F. V. ve Power, M. J. (2007). A new self- report measure of emotion regulation in adolescents: The regulation of emotions questionnaire. Clinical Psychology and Psychotherapy, 14(2), 145-156.

Potek, R. (2012). Mindfulness as a school-based prevention program and its effect on adolescent stress, anxiety and emotion regulation (Yayınlanmamış doktora tezi). New York Üniversitesi, New York.

Scribano, A. (2018). Politics and Emotions. Houston USA: Studium Press llc.

Shahidi, S., Akbari H. ve Zargar, F. (2017). Effectiveness of mindfulness-based stress reduction on emotion regulation and test anxiety in female high school students. Journal of Education and Health Promotion. 6(October), 1-6.

Sperberg, E. D. ve Stabb, S. D. (1998). Depression in women as related to anger and mutuality in relationships. Psychology of Women Quarterly, 22(2), 223-238.

Stevenson, J.C., Millings, A. ve Emerson. (2019). L.M. Mindfulness, 10(2), 256-271. doi: 10.1007/s12671-018-09708

Teasdale, J. D. (1999). Emotional processing, three modes of mind, and the prevention of relapse in depression. Behaviour Research \& Therapy, 37(July), 53-78.

Webb, T. L., Miles, E. ve Sheeran, P. (2012). Dealing with feeling: A meta-analysis of the effectiveness of strategies derived from the process model of emotion regulation. Psychological Bulletin, 138(4), 775-808.

Werner, K. ve Gross, J. J. (2010). Emotion regulation and psychopathology. A. M. Kringand ve D. M. Sloan (Ed.), Emotion regulation and psychopathology: A transdiagnostic approach to etiology and treatment içinde (ss. 13-37). New York: The Guilford Press.

Williams, C. (2007). Research Methods. Journal of Business \& Economics Research (JBER), 5(3), 65-72. doi: 10.19030/jber.v5i3.2532 


\section{EXTENDED ABSTRACT}

\section{Introduction}

Studies of emotion regulation have been showing a rise within the discipline of psychology. The common narrative of these studies is that emotion regulation plays a crucial role in shaping behavioral patterns of individuals in a positive manner if regulated through proper and functional strategies. A common factor in developing positive and functional emotion regulation, as the literature stresses, is mindfulness. So it is quite usual to come across studies dealing with emotion regulation and mindfulness at the same time. These studies emphasize that mindfulness has positive effect on emotion regulation, which has a positive contribution to psychological wellbeing. Individuals who make proper use of these strategies increases their capacity to develop socially acceptable behaviors. In contrast to this, individuals who lack of these strategies face difficulties in emotion regulation. Individuals who lack in abilities of emotion regulation have a higher potential in developing psychopathologies like depression, obesity, and even sexual crimes. (Hoffman, Sawyer, Fang ve Asnaani, 2012; Kaufman et. al., 2015; Sperberg ve Stabb, 1998).

The common argument of these studies is that emotion regulation has a capacity to predict psychopathological risks. Therefor it is utmost important to study the emotion regulation capacities of individuals especially with adolescents, and constructs like mindfulness that predicts emotion regulation. Mindfulness, which is being mindful to present time and everything going on in the present, has a capacity to contribute to develop proper strategies of emotion regulation. The present study puts this claim in test by examining the relationship between emotion regulation and mindfulness among middle school students.

In relation to its aim the study questions;

1. What are the level of mindfulness skills and emotion regulation abilities of middle school students?

2. Is there any meaningful difference between students' mindfulness skills and emotion regulation abilities with respect to their gender and grade levels?

3. Is there a correlation between students' mindfulness skills and emotion regulation abilities?

\section{Method}

This study is a correlational one that seeks to examine the relationship between two artifacts. The population of the study is students of public middle schools (6.-8. graders) in İstanbul. A sample of 400 hundred students from grade levels of 6-8 have been randomly chosen to participate the study. After eliminating the missing data, 345 students' data has been analyzed. The mindfulness scale for children and adolescents questionnaire and emotion regulation scale for adolescents have been used to gather data. Data was analyzed with SPSS 24 by utilizing independent samples t-test, one-way ANOVA and Pearson correlation coefficient.

\section{Results}

Findings of the study indicate that participants have a mid-level mindfulness score $(\bar{X}=2.84, s d=.86)$. Their internal functional emotion regulation mean is satisfactory $(\overline{\mathrm{X}}=4.10$, sd $=.67)$. Their external functional emotion regulation is above average $(\overline{\mathrm{X}}=3.44, \mathrm{sd}=.85)$. Their internal non-functional emotion regulation is around average $(\bar{X}=2.09, \mathrm{sd}=.79)$ and their external non-functional emotion regulation is below average $(\bar{X}=1.55$, $\mathrm{sd}=.54)$.

The results of independent sample t-test showed that there is no difference between male and female participants' scores of emotion regulation and mindfulness. ANOVA test showed that there is no difference in their scores of mindfulness per participants' grade level. ANOVA also showed that there is only meaningful difference in participants' scores of external non-functional emotion regulation with respect to their grade level. There is a meaningful difference between 6. grades' and 8. grades' score of external non-functional emotion regulation $\left(\overline{\mathrm{X}}_{\text {diff }}=-.223, \mathrm{p}=.004\right)$.

Lastly, correlation analysis showed that there is meaningful relationship between mindfulness and emotion regulation. Mindfulness has a positive relation with internal functional emotion regulation ( $\mathrm{r}=.353$, 
$\mathrm{p}<.00)$ and external functional emotion regulation $(\mathrm{r}=.499, \mathrm{p}<.001)$ and a negative relation with internal nonfunctional emotion regulation $(\mathrm{r}=-.299, \mathrm{p}<.001)$ and external non-functional emotion regulation $(\mathrm{r}=-.308$, $\mathrm{p}<.001)$.

\section{Conclusion}

This study examines the relationship between middle school students' mindfulness skills and emotion regulation abilities. Different studies have been implying that deficit of these skills and abilities have a positive impact on developing psychopathologies, which means that proper emotion regulation strategies and mindfulness abilities are very important for psychological wellbeing.

The present study examines three problems in the context of emotion regulation and mindfulness. These problems are the relationship between students' emotion regulation capacities and mindfulness abilities, whether there are any differences in students' abilities with respect to their gender and ages. Results show that students' emotion regulation capacities and mindfulness abilities are average. There is no difference with respect to students' gender and age. Lastly, the study shows that there is a significant relationship between emotion regulation capacities and mindfulness abilities.

The present study shows that there is meaningful relation between emotion regulation and mindfulness. Different studies have been reporting that emotion regulation help students to develop proper behaviors reduce stress level and test anxiety. Out claim is a boost in mindfulness will help students to have sound and healthy emotion regulation strategies as the results of the present study implies. Therefore, we recommend researchers and practitioners to develop mindfulness intervention programs to help students regulate their emotion. 